\title{
LIMITES E PERCEPÇÕES PARA A FORMAÇÃO DO PEDAGOGO HOSPITALAR NO CAMPUS UNIVERSITÁRIO DO MARAJÓ- BREVES-PA.
}

Rayane Cristine da Silva PINHEIRO

Universidade Federal do Pará nany_pinheiro20@hotmail.com

Alexandre Augusto CALS Campus Universitário de Abaetetuba/UFPA alexandre@ufpa.br

Resumo: Este artigo apresenta as políticas públicas educacionais de formação que influenciam na construção do currículo de Pedagogia em Breves, e suas implicações para atuarem em ambientes hospitalares. $O$ estudo buscou analisar as políticas públicas para a formação do pedagogo no ambiente hospitalar. Foi utilizada a análise documental, entrevistas e questionários que foram empregados para uma amostra de $15 \%$ dos alunos egressos das turmas de 2006 a 2008 e com alunos egressos que realizaram trabalhos na área da Pedagogia Hospitalar. O aporte teórico utilizado, ancorou-se nas pesquisas de Brandão (2007), Brzezinski (2011), Diniz (2010), entre outros. Os resultados obtidos nos mostram que mesmo habilitados para atuar na área hospitalar, eles não têm um suporte teórico e prático suficiente para atuarem nos hospitais, mesmo reconhecendo a importância desta atuação eles têm dificuldades de descrever as ações que o pedagogo desenvolve neste ambiente.

Palavras-Chave: Políticas Públicas. Formação. Pedagogia Hospitalar.
Resumen: Este artículo presenta las políticas públicas de formación educativos que influyen en la construcción del plan de estudios de Pedagogía, y sus implicaciones para trabajar en los entornos hospitalarios. El estudio trata de analizar las políticas públicas para la formación del pedagogo en el hospital. Se utilizó el análisis de documentos, entrevistas y cuestionarios que se aplicaron a una muestra de 15\% de los estudiantes que se gradúan clases del año 2006 hasta 2008, y ex-alumnos que han realizado trabajos en el área de Pedagogía Hospitalaria. El enfoque teórico, se ancló en la investigación Brandão (2007), Brzezinski (2011), Diniz (2010), entre otros. Los resultados nos muestran que nesmo cualificados para trabajar en el hospital, no tienen un soporte bastante teórica y práctica para trabajar en los hospitales, al tiempo que reconoce la importancia de esta actividad tienen dificultades para describir las acciones que el profesor desarrolla este entorno en el que ve una imagen fija orientada formación sólo para la enseñanza en este espacio.

Palabras-clave: Políticas públicas. Amazonas. la ciudad de la tierra. 


\section{Introdução}

Ao se buscar discutir a identidade do pedagogo hospitalar que vem engajada dentro destes novos campos de atuação que fecundam a pedagogia, mostrou-se necessário analisarmos e compreendermos como está pautada a formação dos pedagogos, cujo curso, muitas vezes é confundido como exclusivamente de formação de professores. Percebemos ainda, nos Cursos de Pedagogia, um currículo voltado em sua grande maioria para a formação do pedagogo para instituições escolares, deixando de lado outros campos de atuação que ultrapassam os limites da escola.

As Faculdades de Educação, nas quais estão atrelados os Cursos de Pedagogia, apesar de "habilitarem" seus alunos para os mais diversos contextos que perpassam a prática pedagógica, ainda possuem preocupação de formar o pedagogo apenas para a docência, enquanto outros campos são encarados como elementos de formação secundários, e o campo científico-investigativo da pedagogia, enquanto ciência da educação é visto em segundo plano.

Porém, esta organização curricular dos cursos atrelados à educação são reflexos das políticas públicas educacionais, que são as quais servem de embasamento para a organização e elaboração dos Projetos Pedagógicos de Curso. Tais políticas refletem não apenas as ideologias da época em que foram criadas, como também servem de arcabouço para compreendermos os modelos das políticas atuais, cujo resultado pode confrontar-se diretamente com a visão que é traçada frente a estes profissionais. Possibilitando ainda, entender possíveis distorções ocorridas na identidade do Curso de Pedagogia, com a adoção de um "caráter reducionista e simplista", como afirma Libâneo (2010), delimitado pelas políticas de formação, que institui um modelo curricular voltado apenas para a formação de professores, ao qual não engloba de forma concisa, a complexidade que é o trabalho pedagógico e docente e as diversas "educações".

Neste sentido, o presente estudo faz uma análise das políticas púbicas de formação do Curso de Pedagogia, e de que forma estas políticas influenciam na construção do currículo do Campus Universitário do Marajó - Breves para formação do pedagogo hospitalar. 


\section{As políticas públicas de formação para os profissionais da educação}

Para compreendermos o Curso de Pedagogia como está estruturado atualmente, precisamos adentrar nas discussões referentes às políticas públicas de educação que foram proeminentes para o modelo de desenho curricular do qual iremos debater, principalmente no que refere a identidade do pedagogo e sua atuação em ambientes hospitalares.

De acordo com Diniz (2010) as políticas de formação dos profissionais da educação no país têm seu início ainda no período da colonização, quando recebiam uma formação voltada à instrução religiosa, para ensinar as quatro operações, escrever, ler e noções de gramáticas.

Significativas medidas de mudanças referentes à formação dos profissionais da educação começaram a se desatar a partir do século $\mathrm{XX}$, com a criação da $\mathrm{ABE}$ (Associação Brasileira de Educação), em 1931, em que ocorre a IV Conferência Nacional de Educação, com a finalidade de discutir os problemas relacionados à educação, como também a relevância de definir políticas nacionais para este setor. O que impulsiona a formulação do documento conhecido como "Manifesto dos Pioneiros da Escola Nova".

Entre outras atribuições levantadas neste documento, os escolanovistas destacavam preocupações por parte de formar os profissionais da educação em nível superior. Partindo deste contexto, surge através do decreto Lei $n^{\circ} 1.190$ de 4 de abril de 1939, o Curso de Pedagogia, estabelecendo a formação de professores em nível superior. $\mathrm{O}$ decreto outorga formação do curso em dois eixos: um para formar o bacharel e outro para a formação do licenciado em pedagogia, seguindo o esquema $3+1$. Quanto a este esquema $3+1$, Brzezinski (2011, p. 24), ressalta que:

A identidade do pedagogo, então, revelava-se dicotômica, entre ser técnico e ser professor. A ambivalência na identidade derivava de uma situação curricular estranha em que o conteúdo da pedagogia era dissociado do conteúdo da didática e os cursos eram distintos, provocando a ruptura entre conteúdo dos conhecimentos epistemológicos específicos do campo da pedagogia e o método de ensinar esse conteúdo. 
A autora nos mostra que o Curso já se inicia com uma identidade distorcida do que é a pedagogia como ciência da educação, voltada para a docência, dissociando conteúdo e método, teoria e prática, que são refletidas nas ações cotidianas desses profissionais. Identidade está concretizada pelos pareceres 251/1962 e 252/1969, em que regulamentou o currículo mínimo para o Curso de Pedagogia, com intuito de definir sua identidade, voltada para as habilitações (supervisão, orientação, administração e inspeção educacional) e fixaram os conteúdos mínimos e a duração do curso para a formação pedagógica. Brzezinski (2011) evidencia que estas reformulações do Curso afirmam a ideologia alienante que transfere para a educação a mesma organização do trabalho produtivo de uma fábrica de montagem, ao fragmentar e aderir um caráter tecnicista de formação, simplista e reducionista, com um currículo pautado nas especializações.

Com a Lei 9.394/96 abarcando de forma mais geral a educação e sua organização, iniciam inúmeras críticas e debates com intuito de definir uma identidade ao Curso e a introdução de um currículo a delinear as reais perspectivas do que é a pedagogia. Tais ações impulsionam a criação das Diretrizes Curriculares para o Curso de Pedagogia (DCNP), as qual instituem o desenho curricular do curso e sua identidade.

\section{As Diretrizes Curriculares para o Curso de Pedagogia e a formação do pedagogo hospitalar}

As diretrizes homologadas pelo Parecer CNE/CP 05/2005 e pela Resolução CNE/CP 1/2006 delineiam rumos mais abrangentes de formação. Sheibe (2007) ressalta que este parecer mostra grandes avanços na formação, pois amplia seus objetivos e torna-se claro o propósito do curso, ao assumir a docência como foco de formação e introduzir uma abrangência maior no que diz respeito ao trabalho pedagógico, com atividades que extrapolam as instituições escolares e abarcam os espaços não escolares.

Todavia, ainda traz discrepâncias no que concerne a Pedagogia em si e como foi descrita nas DCNP. Como ao atribuir ao Curso de Pedagogia um conceito limitado de sua prática ao assumir que a identidade do curso é a docência, ao mesmo tempo adere um 
caráter polivalente no curso, o que para nós, constitui-se em uma visão limitada da abrangência do curso de pedagogia.

Libâneo (2010), afirma que este "reducionismo e simplismo" aderido ao Curso de Pedagogia, voltado apenas à formação de professores, atua como uma limitação do que é de fato a pedagogia, na qual deve acompanhar as mudanças ocorridas na sociedade. Se por determinado momento histórico seria necessário atribuir ao trabalho pedagógico como uma prática docente, nos contextos atuais da educação brasileira estas atribuições limitam o trabalho pedagógico, que atingem um campo maior de conhecimento e requer uma política de formação mais ampliada. Consoante a estas proposições Pimenta (2006, p. 60) sinaliza que,

Há uma diversidade de práticas educativas na sociedade que se realizam em muitos lugares sob várias modalidades. Como toda educação corresponde uma pedagogia, também há uma diversidade de trabalhos pedagógicos para além das atividades de educação escolar e ensino

Sendo assim, corrobora-se a proeminência de agregar discussões para formular um currículo para o Curso de Pedagogia que considere de fato uma formação adequada de atuação também para os ambientes não escolares, principalmente naqueles nas quais suas práticas podem ressignificar totalmente um ambiente considerado negativo, por conta da doença e da dor, como ocorre nos ambientes hospitalares, palco central de nossa discussão.

A Pedagogia Hospitalar atua a partir da integração entre teoria e prática, no redirecionamento de estratégias educativas as quais propiciem esse caráter humanista e educativo também na relação dos profissionais da saúde, com os familiares e as crianças e adolescentes hospitalizados, a fim de modificar hábitos e relações onde os pacientes são vistos a partir de sua patologia e não como um ser humano ativo, munido de direitos, autônomo e participante do seu processo de recuperação.

Fontes (2004) nos ressalta sobre esta distância existente entre a necessidade de atuação deste profissional que atua nos hospitais com sua formação que ainda não dispõe de caráter teórico-investigativo suficientes que possibilite a construção de uma práxis do pedagogo junto a criança hospitalizada. Além disto, as políticas de formação não propiciam orientação condizentes a um atendimento especializado, para pessoas com necessidades 
educativas especiais onde se encontram a criança e o adolescente hospitalizados (MATOS, 1998).

Verificada esta necessidade de inserção do pedagogo, chegamos ao objeto de estudo deste trabalho que é analisar se os egressos do Curso de Pedagogia do Campus Universitário do Marajó, em Breves, reconhecem e se sentem preparados para este novo cenário de atuação pedagógica. Para emergir esta discussão temos como ponto fundamental as bases legais que orientam a construção do currículo deste curso e seus reflexos na formação destes acadêmicos para o ambiente hospitalar.

\section{Trajetória da pesquisa}

O interesse pela pesquisa durante a graduação do curso de Pedagogia no campus citado se motiva pelo fato de que até meados do curso não houve nenhuma discussão no que refere a esta área de atuação do pedagogo. E ainda pelas dificuldades em encontrar na Faculdade de Educação do Campus Universitário do Marajó-Breves (CUMB) um professor que orientasse trabalhos nesta área de atuação.

Tendo em vista, estas e outras dificuldades relacionadas ao suporte teórico sobre a Pedagogia Hospitalar, passamos então a questionar sobre a formação dos alunos de Pedagogia do CUMB para o ambiente hospitalar e verificamos que o curso habilita para as diversas áreas de atuação pedagógica, no entanto muitos alunos do curso não tinham conhecimento referente a esta área de atuação, a hospitalar.

Assim, a pesquisa foi realizada com alunos egressos do Curso de Pedagogia do Campus Universitário do Marajó-Breves (CUMB). Os dados e discussões aqui analisados levaram em consideração as turmas do curso de Pedagogia dos anos de 2006 a 2008, pois se pretendeu focar na análise da formação do Pedagogo para o ambiente hospitalar e esta se mostra de forma mais concisa a partir do Parecer do CNE/CP $\mathrm{n}^{\circ}$ 5/2005 e por meio da Resolução do CNE/CP N 1/2006.

Visto que, até a data de publicação deste trabalho estas turmas já terão concluído o Curso, podemos analisar, também, as percepções dos egressos do Curso referente à sua formação para atuar no ambiente hospitalar. 
Foram aplicados questionários para 15\% dos alunos egressos (14 alunos) e ainda foram realizadas entrevistas com alunos egressos os quais realizaram pesquisa na área da Pedagogia Hospitalar (Sete alunos egressos no total). Esta amostra julgou-se suficiente para levantar dados referentes à visão destes alunos sobre a sua formação para o ambiente hospitalar. Cabe ressaltar que para preservar a identidade dos sujeitos substituímos seus nomes pela palavra "pedagogo" e acrescentado uma enumeração para diferenciar os mesmos.

\section{Implicações e análises das políticas públicas para a formação do pedagogo hospitalar no Curso de Pedagogia do CUMB}

As leituras de trabalhos acerca do PPC (Projeto Pedagógico de Curso) de Pedagogia nos mostram forte influência dos discursos defendidos pela ANFOPE, que defendem a docência como base da identidade do profissional formado em Pedagogia, responsável pela Educação Infantil e nas séries iniciais do Ensino Fundamental.

A Resolução N 2669/99 do CONSEPE (Conselho Superior de Ensino e Pesquisa), a qual define o currículo do Curso de Pedagogia, deu bases para a formulação do PPC de 1999 da Faculdade de Educação, foco de nosso trabalho, em vigor até o ano de 2010, denota que os alunos formados possuem embasamento teórico e prático para atuarem em diversos ambientes, sejam formais e informais, inclusive o hospitalar, o que nos indica a uma formação a qual tenta abarcar os diversos campos de atuação pedagógica, buscando assim uma formação totalizante e não mais especialista como propunham os Pareceres 252/69 de Valnir Chagas.

Nessa perspectiva, os egressos do Curso de Pedagogia têm embasamento teórico e prático para atuarem nos diversos ambientes escolares e não escolares, inclusive no ambiente hospitalar, construídos durante sua formação no Curso. Porém, a análise das disciplinas e ementas dos núcleos nos mostrou contradições entre a teoria e objetivos iniciais traçados, com as especificações explicitadas em suas ementas e disciplinas, mais uma vez voltadas para o ambiente escolar, como traduz a LDB 9394/96, apoiada pela Resolução 2669/99. 
No curso de Pedagogia em Breves até o ano de 2008, a única disciplina deste Núcleo que remete ao embasamento teórico para o ambiente hospitalar é a disciplina "Pedagogia em Ambientes não escolares". Quanto à disciplina a abordar sobre a Pedagogia Hospitalar segundo a visão do Pedagogo 6:

Esta disciplina apenas apresentou as possibilidades de atuação do pedagogo em outras áreas e de forma muito superficial. Dada a complexidade e especificidade da formação para atuação no ambiente hospitalar, mesmo tendo atuado em tal ambiente, acredito que os profissionais graduados no CUMB enfrentam bastantes dificuldades nestes espaços (Pedagogo 6).

Há de ressaltar ainda as impressões dos alunos egressos que consideraram a formação teórica muito restrita. Eles afirmam em suas falas que durante o Curso de Pedagogia, julgaram terem tido uma disciplina voltada diretamente para esta área, “[...] o fato é que o currículo do Curso de Pedagogia não nos permitiu ampliação de conhecimento nesta área e também não houve nenhum embasamento prático para que pudéssemos atuar na mesma" (Pedagogo 5).

Observamos que $40 \%$ dos entrevistados descrevem as múltiplas ações do pedagogo no ambiente hospitalar, sendo que a maior parte destes, ou seja, $80 \%$ foram os alunos aos quais desenvolveram o Trabalho de Conclusão de Curso na área hospitalar, muitos deles afirmam que ampliaram seu conhecimento a respeito da Pedagogia Hospitalar a partir da pesquisa bibliográficas desenvolvidas na elaboração dos trabalhos.

Chama-nos a atenção ainda que $50 \%$ dos alunos possuem uma visão restrita da atuação do pedagogo e atribuem a atuação voltada para uma atividade mantenedora da escolarização, desconhecendo outras práticas de atuação dentro deste ambiente e outras especificidades deste trabalho. Os outros $10 \%$ não conseguiram descrever a atuação do pedagogo nos hospitais.

No que diz respeito ao suporte teórico e prático, destacaram que a formação teórica adquirida no curso foi suficiente, ou seja, $40 \%$ compactuam da ideia de que outras disciplinas não necessariamente ligadas ao ambiente hospitalar dão bases para a elaboração de práticas dentro deste novo cenário, como afirma o Pedagogo 8:

O curso de Pedagogia é bastante estimulante a proposições criativas no que tange aos aspectos teóricos, em razão das leituras filosóficas, 
sociológicas, psicológicas, históricas, antropológicas que nos são introduzidas, permitindo-nos abrangência ou mudanças de ver e entender os fatos, tendo maior criticidade.

Referente à prática na área, a mesma não ocorreu por meio de estágios, mas de ações de intervenção nos principais hospitais, tendo a duração de 4 horas. Os alunos ressaltaram que uma das dificuldades enfrentadas para atuar de forma prática é a relacionada com a baixa carga horária da disciplina e da "ausência de espaços adequados nos hospitais destinados ao pedagogo para que eles possam realizar suas atividades" (Pedagogo 1).

Os trabalhos de Conclusão de Curso (TCC) do CUMB realizadas na área da Pedagogia Hospitalar (Machado e Lima, 2008; Souza e Pinto, 2010) enfocaram as dificuldades de adentrar neste espaço e frisam que no município de Breves e demais municípios do Marajó há ausência de pedagogos atuando, o que é comprovado com esta pesquisa na qual nenhum dos egressos do curso atua em hospitais.

No concernente ao curso de Pedagogia, mesmo trazendo uma visão ainda muito superficial sobre a Pedagogia Hospitalar, quando analisados os TCC's sobre esta área verificamos que a disciplina Pedagogia em Ambientes não Escolares foi substancial para suscitar nos estudantes o interesse pelo tema.

As análises acerca das percepções levantadas pelos educandos nos levam a compreender que a maior parte reconhece a complexidade e desafio que é trabalhar em hospitais, assim como a importância desta atuação pedagógica em tais espaços. No entanto, espera-se que os resultados obtidos nesta pesquisa sejam referendados como diagnóstico e reflexão sobre o Curso de Pedagogia e sobre a formação para o ambiente hospitalar, impulsionando novas pesquisas nesta área de atuação e chamando a atenção do olhar para o profissional da educação o qual se pretende formar no curso de Pedagogia.

\section{Considerações}

Percebemos durante a pesquisa que o curso de Pedagogia, apesar de inúmeros avanços alcançados nas políticas de formação, ainda necessita acompanhar e destacar os 
diversos campos de atuação do pedagogo, entre eles o hospitalar, assim como é necessário superar-se a concepção de atuação voltada apenas à docência para os ambientes escolares. Apesar das mais recentes diretrizes trazerem em alguns artigos entendimentos que se referem à prática para novas atuações, elas deixam também lacunas principalmente no tocante à estrutura curricular dos cursos, nos quais permanece, em sua maioria, a predominância de disciplinas voltadas para o ambiente escolar.

A prática educacional nos hospitais não deve ser encarada apenas como mais um leque de atuação pedagógica, mas também como um espaço que remete a novas possibilidades as quais necessitam de um diferencial tanto no processo de formação dos pedagogos como na estruturação dos cursos de Pedagogia. Nesse sentido, a formação do pedagogo deve ter por base a inserção entre teoria e prática, fator relevante de transformação da realidade.

A pesquisa nos mostrou ainda que mesmo os egressos saindo habilitados a atuar no ambiente hospitalar, o termo Pedagogia Hospitalar não aparece em nenhum dos núcleos ou ementas das disciplinas. Temos por base no currículo para esta formação apenas uma disciplina específica a qual trata de todas as áreas de atuação para os ambientes não escolares. Neste enfoque, há muita similaridade com políticas nas quais prevaleceu uma formação fundada em currículos mínimos, com conteúdos mínimos, principalmente quando tratamos da formação do pedagogo para atuar nos hospitais.

Nos depoimentos dos alunos egressos vimos que apesar de terem demonstrado conhecimento sobre a Pedagogia Hospitalar muitos tiveram dificuldades em elencar de que forma o pedagogo atua e quais as práticas que desenvolve nos hospitais e seus objetivos. As percepções levantadas pelos pesquisados mostraram que ainda veem a atuação no ambiente hospitalar como se fosse um complemento ou continuidade do ambiente escolar e o hospital neste contexto resume-se à ação de mantenedor da escolarização, sendo que esta é apenas uma das atribuições do pedagogo no ambiente hospitalar.

Assim, o curso de Pedagogia precisa de uma nova proposta curricular que abarque a Pedagogia Hospitalar, porém, mais do que uma reestruturação do curso, necessita-se de uma articulação maior por parte dos acadêmicos e profissionais da saúde que questionem e investiguem nesta área, para a mesma poder tomar as devidas proporções e relevância mais 
consistente nos cursos de Pedagogia, consequentemente impulsionando a elaboração de novas políticas de formação dos profissionais da educação que ressaltem tal proeminência.

O PPC atual do curso de Pedagogia do CUMB, que data do ano de 2010, mostra significativos avanços na formação do pedagogo para o ambiente hospitalar, pois o mesmo já traz em sua estrutura curricular o estágio voltado para os ambientes não escolares, como é o caso dos hospitais, além da disciplina teórica para os ambientes não escolares. Todavia, apesar de ser mais atual, este necessita ser revisado e organizado de maneira que além de destacar a preocupação de integrar teoria e prática de forma equilibrada no currículo, possa também organizar o PPC de forma que as disciplinas para os ambientes escolares e não escolares, como a Pedagogia Hospitalar, tenham o mesmo patamar de importância no currículo e na formação do pedagogo.

Este seria um ganho não apenas para o curso de Pedagogia, pois as produções para outras áreas até então pouco pesquisadas como a área hospitalar seriam mais discutidas e referendadas, como ainda para os pedagogos os quais teriam abertura de espaços de atuação para outros ambientes, sempre levando em consideração todos os aspectos pertinentes e substanciais da Pedagogia enquanto teoria e prática da educação.

\section{Referências:}

BRASIL. Lei n. 9.394, de 20 de dezembro de 1996: Estabelece as Diretrizes e Bases da Educação Nacional. Brasília, 20 dez.1996. Disponível em: <http://www.planalto.gov.br/ccivil_03/leis/19394.htm>. Acesso: 26/03/2013.

Parecer CNE 5/2005: estabelece as Diretrizes Curriculares para o Curso de Pedagogia. Brasília, 2005. Disponível em: <http://portal.mec.gov.br/cne/arquivos/pdf/pcp05_05.pdf $>$. Acesso em: 11/08/2011.

Parecer CNE/CP 3/ 2006. Reexame do Parecer CNE/CP n ${ }^{\circ}$ 5/2005, que trata das Diretrizes Curriculares Nacionais para o Curso de Pedagogia. Disponível em: <http://portal.mec.gov.br/cne/arquivos/pdf/pcp003 06.pdf>. Acesso em: 11/08/2011

BRANDÃO, Carlos Rodrigues. O que é educação? 20 ed. São Paulo: Brasiliense, 2007. (Coleção Primeiros Passos) 
BRZEZINSKI, Iria. Pedagogo: Delineando Identidade(s). Revista UFG. Ano XIII n ${ }^{\circ} 10$ Julho, 2011. p. 120-132.

DINIZ, Maria de Fátima Chagas. O (a) acadêmico (a) do curso de Pedagogia e suas expectativas profissionais no Século XXI: um estudo com os alunos (as) do curso de Pedagogia 2006/2009 da Faculdade Padrão do município de Goiânia - Goiás. Dissertação (mestrado) - Pontifícia Universidade Católica de Goiás, Goiânia, 2010. 109f.

FACULDADE DE EDUCAÇÃO-UFPA. Diagnóstico do Curso de Pedagogia sob a vigência do PPP de 1999. Universidade Federal do Pará: Breves, 2010.

FONTES, Rejane de Souza. A reinvenção da escola a partir de uma experiência instituinte em hospital. Educação e Pesquisa. São Paulo, v.30, n.2, p. 271-282, maio/ago. 2004.

LIBÂNEO, José Carlos. Pedagogia e Pedagogos, para quê? 12 ed. São Paulo: Cortez, 2010.

MATOS, Elizete L. MUGGIATI, Margarida M. Pedagogia hospitalar: a humanização integrando educação e saúde. 4 ed. Petrópolis, RJ: Vozes, 2009.

MATOS, Elizete L. M. TORRES, Patrícia L. (Orgs.). Teoria e prática na Pedagogia Hospitalar: novos cenários, novos desafios. Curitiba: Champagnat, 2010.

PIMENTA (org.), Selma Garrido. Pedagogia e Pedagogos: caminhos e perspectivas. 2 ed. São Paulo: Cortez, 2006

UNIVERSIDADE FEDERAL DO PARÁ. Resolução $N^{o}$ 2669/99: Define o currículo do Curso de Licenciatura Plena em Pedagogia. Universidade Federal do Pará: Belém, 1999b. Disponível em: <http://www.ufpa.br/cubt/publicacoes/documento/faecs/Pedagogia/ resolucao.pdf $>$. Acesso em: 23/02/2013. 